\title{
Augmentation of neovascularization in murine hindlimb ischemia by combined therapy with simvastatin and bone marrow-derived mesenchymal stem cells transplantation
}

Yong $\mathrm{Li}^{1,2+}$, Dingguo Zhang ${ }^{3+}$, Yuqing Zhang ${ }^{4+}$, Guoping He${ }^{2}$, Fumin Zhang ${ }^{1 *}$

\begin{abstract}
Objectives: We postulated that combining high-dose simvastatin with bone marrow derived-mesenchymal stem cells (MSCs) delivery may give better prognosis in a mouse hindlimb ischemia model.

Methods: Mouse hindlimb ischemia model was established by ligating the right femoral artery. Animals were grouped $(n=10)$ to receive local injection of saline without cells (control and simvastatin groups) or with $5 \times 10^{6}$ MSCs (MSCs group).Animals received either simvastatin ( $20 \mathrm{mg} / \mathrm{kg} / \mathrm{d}$, simvastatin and combination groups) or saline (control and MSCs group) gavages for continual 21 days. The blood flow was assessed by laser Doppler imaging at day 0,10 and 21 after surgery, respectively. Ischemic muscle was harvested for immunohistological assessments and for VEGF protein detection using western blot assay at 21 days post-surgery. In vitro, MSCs viability was measured by MTT and flow cytometry following culture in serum-free medium for $24 \mathrm{~h}$ with or without simvastatin. Release of VEGF by MSCs incubated with different doses of simvastatin was assayed using ELISA.
\end{abstract}

Results: Combined treatment with simvastatin and MSCs induced a significant improvement in blood reperfusion, a notable increase in capillary density, a highest level of VEGF protein and a significant decrease in muscle cell apoptosis compared with other groups. In vitro, simvastatin inhibited MSCs apoptosis and increased VEGF release by MSCS.

Conclusions: Combination therapy with high-dose simvastatin and bone marrow-derived MSCs would augment functional neovascularization in a mouse model of hindlimb ischemia.

\section{Introduction}

Peripheral arterial disease (PAD) is one of the most common clinical manifestations of atherosclerosis, which affects a significant number of individuals. It represents an important cause of disability and is associated with elevated cardiovascular morbidity and mortality[1]. Treatment of PAD includes anticoagulants and antiplatelet drugs, percutaneous transluminal angioplasty, and bypass surgery. However, the prognosis for patients with PAD still remains poor, and amputation of the lower extremities is often required [2]. Several types of stem

\footnotetext{
* Correspondence: zhdg0223@126.com

+ Contributed equally

'Department of Cardiology, the First Affiliated Hospital of Nanjing Medical University, 210029, R.R. China

Full list of author information is available at the end of the article
}

cells have been used for therapeutic neovascularization, including the bone marrow-derived mesenchymal stem cells (MSCs), which have attracted a great attention from investigators because of their plasticity and availability[3]. These cells mediate their therapeutic effects by homing to and integrating into injured tissues, differentiating into endothelial cells, and/or producing paracrine growth factors. However, recent studies have shown that patients with PAD are often coincident with cardiovascular risk factors, such as aging, diabetes mellitus, which reduce the availability of progenitor cells and impair their function to varying degrees [4-6], likely limiting the efficiency of stem cell therapy. Therefore, optimization of strategies to improve the therapeutic potential of cell therapy needs to 
be developed to augment application of this technology for patients with cardiovascular diseases.

Statins are 3-hydroxy-3-methyl-glutaryl-CoA reductase inhibitors and are primarily used to lower circulating cholesterol levels. In addition, studies have revealed statin's pleiotropic effects, such as the protection of endothelial function, increased nitric oxide bioavailability, antioxidant effects, anti-inflammatory reaction, and stabilization of atherosclerotic plaques[7,8]. Recent studies have demonstrated that statins could protect against ischemic injury of the heart [9] and stimulate angiogenesis in ischemic limbs of normocholesterolemic animals [10]. However, both in vitro and in vivo studies have suggested a biphasic and dose-dependent effect of statins on angiogenesis [11]. Yang demonstrated that low-dose simvastatin could enhance the therapeutic effects of bone marrow cells in pig's acute myocardial infarction model [12]. Whereas, some studies indicated that high-dose statins could also enhance angiogenesis in vivo [13]. Accordingly, we investigated whether the combination therapy with high-dose simvastatin administration and MSCs transplantation could augment functional neovascularization in a mouse model of hind limb ischemia.

\section{Materials and methods \\ Animals}

Adult male Sprague-Dawley rats (80-100 g) were purchased from Slac company (Shanghai, China).Adult female C57BL/6J mice (8 weeks, 20-25 g) were provided by the Model Animal Research Center of Nanjing University (Nanjing, China). All animal experimental protocols were approved by the Animal Care and Use Committee of Nanjing Medical University and were in compliance with Guidelines for the Care and Use of Laboratory Animals, as published by the National Academy Press (NIH Publication No. 85-23, revised 1996)

\section{Isolation, expansion and labeling of MSCs}

Rat MSCs were isolated with a modified procedure as described previously [14]. In brief, Sprague-Dawley rats were sacrificed by cervical dislocation. Femora and tibia were aseptically harvested. Whole marrow cells were obtained by flushing the bone marrow cavity with low glucose Dulbecco's Modified Eagle's Medium (L-DMEM, Hyclone, USA). Cells were centrifuged at $1000 \times g$ for 5 minutes and the supernatant was removed. The cell pellet was then re-suspended with L-DMEM supplemented with $10 \%$ fetal bovine serum (FBS, Hyclone, USA), $100 \mathrm{U} / \mathrm{ml}$ penicillin (Gibco,USA), $100 \mathrm{U} / \mathrm{ml}$ streptomycin (Gibco,USA), and incubated at $37^{\circ} \mathrm{C}$ in a $5 \% \mathrm{CO}_{2}$ atmosphere. After 24 hours, non-adherent cells in suspension were discarded and culture media was changed every three or four days thereafter. When MSCs reached
$70 \%-80 \%$ of confluence, they were trypsinized by the addition of $0.25 \%$ trypsin-EDTA (Sigma-Aldrich, USA), and then re-plated in culture flasks. Cells between $3^{\text {rd }}$ and $6^{\text {th }}$ passage were utilized for experiment.

\section{Mouse Model of Unilateral Hindlimb Ischemia}

Unilateral hindlimb ischemia was created in 8-week-old female C57BL/6J mice as described previously $[15,16]$. Briefly, mice were anesthetized with pentobarbital (50 $\mathrm{mg} / \mathrm{kg}$, intraperitoneally) and the right femoral artery was dissected free along its entire length. All branches were ligated and excised. The left hindlimb was kept intact and used as the nonischemic limb.

\section{Simvastatin administration and MSCs transplantation}

Simvastatin administration and MSCs transplantation were performed immediately after hindlimb ischemia was created. Simvastatin ( $20 \mathrm{mg} / \mathrm{kg}$ per day) or vehicle (saline) was administered every day by gavage for 21 days. MSCs $\left(5 \times 10^{6}\right.$ cells $/ 50 \mu \mathrm{l}$ per mouse) or $50 \mu \mathrm{l}$ saline was injected into the ischemic thigh muscle with a 26-gauge needle at five different points. This protocol resulted in the creation of four groups ( $n=10$ /group): (1) vehicle administration plus saline injection (control group), (2) simvastatin administration plus saline injection (simvastatin group), (3) vehicle administration plus MSCs transplantation (MSCs group), (4) simvastatin administration plus MSCs transplantation (combination group). Simvastatin was kindly donated by Merck \& Co., Inc., USA. MSCs were labeled with 1,1'-dioctadecyl3,3,3'3'-testramethylindo-carbocyanine perchlorate (DiI) before transplantation as described previously[17]. Briefly, $2 \mu \mathrm{g} / \mathrm{ml}$ DiI was added to cells suspension and incubated at $37^{\circ} \mathrm{C}$ for 5 minutes, then at $4^{\circ} \mathrm{C}$ for $15 \mathrm{~min}$ utes with occasional mixing. MSCs labeled with DiI were washed 3 times with PBS and then collected.

\section{Laser Doppler blood perfusion analysis}

The ratio of ischemic/normal hindlimb blood flow was measured using laser Doppler blood perfusion imager (PeriScan PIM 3, Swenden) as described previously $[15,16]$.Low to no flow was displayed as dark blue, whereas high blood flow was displayed as red to white. Previous study has demonstrated [16] that hindlimb blood flow was progressively augmented over the course of 14 days, ultimately reaching a plateau between 21 and 28 days in mouse hindlimb ischemia model. Therefore, at three predetermined time points (immediately after surgery, and on postoperative days 10 and 21), we performed 2 consecutive laser scanning over the same region of interest (legs and feet). The average flow of the ischemic and nonischemic legs was calculated on the basis of histograms of the colored pixels. To minimize variations due to ambient light, blood flow was 
expressed as the ischemic (right)/normal (left) limb flow ratio.

\section{Histological assessment for capillary density}

Ischemic limb muscles were harvested at day 21 after treatment and embedded in optimal cutting temperature compound. Frozen tissue sections of $5 \mu \mathrm{m}$-thick were stained for alkaline phosphatase [18] to examine the capillary density. To ensure that the capillary densities were not overestimated as a consequence of myocyte atrophy or underestimated because of interstitial edema, the capillary/muscle fiber ratio was determined.

\section{Terminal deoxynucleotidy 1 transferase-mediated dUTP nick end-labeling assay}

The terminal deoxynucleotidy 1 transferase-mediated dUTP nick end-labeling (TUNEL) assay was performed to determine apoptotic activity in hindlimb ischemic tissues using an In Situ Cell Death Detection Kit (Roche, Germany) according to the manufacturer's instructions. Cells in which the nucleus was stained brown were defined as TUNEL-positive and the percentage of apoptotic cells per total number of cells was determined by two independent blinded investigators.

\section{Western blot analysis for the expression of VEGF protein in vivo}

Lysates from hind limb muscle tissue homogenates harvested at day 21 post-surgery were used for Western blot analysis as described previously[19].Protein was analyzed using $10 \%$ sodium dodecyl sulphate-polyacrylamide gel electrophoresis (SDS-PAGE) and transferred to nitrocellulose membranes (Bio-Rad).Membranes were then incubated with primary antibodies including VEGF (1:1000, Cell Signaling) and $\beta$-actin (1:5000, Sigma) at $4^{\circ}$ $\mathrm{C}$ overnight respectively. The membranes were then incubated with peroxidase labeled secondary antibody $\left(1: 1000\right.$, Santa Cruz, USA) at $37^{\circ} \mathrm{C}$ for 2 hours. Signals were detected by enhanced chemiluminescence (Amersham, USA). Densitometric analysis for the blots was performed with NIH image software.

Effect of simvastatin on the cell viability of bone marrowderived MSCs in vitro

To examine whether simvastatin has anti-apoptotic effect on bone marrow-derived MSCs under hypoxia stress, cells viability was detected by MTT assay and flow cytometry measurement, respectively. Cells $(1 \times$ $10^{4}$ cells) were cultured in serum-free medium for $24 \mathrm{~h}$ with $0.01 \mu \mathrm{mol} / \mathrm{L}$ of simvastatin, $0.01 \mu \mathrm{mol} / \mathrm{L}$ of simvastatin plus $50 \mathrm{n} \mathrm{M}$ of wortmannin (phosphatidylinositol 3-kinase, PI3-K, inhibitor), or blank control. Cell viability was evaluated using the MTT assay (MTT, Sigma) and flow cytometry (Becton Dickinson) according to the manufacturer's instructions.

\section{Effect of simvastatin on the release of VEGF of bone marrow-derived MSCs in vitro}

To examine whether simvastatin enhance the release of VEGF by bone marrow-derived MSCs, a total of $1 \times 10^{4}$ MSCs were plated in serum-free medium with different doses of simvastatin $(0,0.001,0.01,0.1$ and $1.0 \mu \mathrm{mol} / \mathrm{L})$ on 48-well plates. VEGF levels in conditioned medium were measured with VEGF ELISA kits (R\&D Systems) $24 \mathrm{~h}$ after treatment.

\section{Statistical analysis}

All values were expressed as mean \pm SD. Student's unpaired $t$ test was used to compare differences between every two groups. Comparisons of parameters among three or four groups were made by one-way ANOVA, followed by Scheffe' multiple comparison test. Comparisons of the time course of the LDPI index were made by 2-way ANOVA for repeated measures, followed by Scheffe' multiple comparison tests. A probability value $<0.05$ was considered statistically significant.

\section{Results}

Identification of bone marrow-derived MSCs

During the primary cell culture, the attached cells stretched and took the shape of a typical spindle-shaped fibroblast phenotype. These adherent cells could be readily expanded in vitro by successive cycles of trypsinization, seeding and culture every 3 days for 15 passages without visible morphologic change. Flow cytometry examination showed that these cells were negative for CD34 and CD45, but positive for CD44 and CD29 (Fig. 1). Thus, we designated these fibroblasts-like cell populations as MSCs.

\section{Combination therapy increases blood perfusion}

To determine whether simvastatin or MSCs treatment could stimulate the blood reperfusion in ischemic limb, mice were treated with simvastatin or MSCs or vehicle, the blood reperfusion was examined at day 0,10 and 21 after the treatment by LDPI. LDPI showed that blood flow in the ischemic hindlimb was decreased equally in all four groups immediately after surgery. Over the subsequent 21 days, blood perfusion of the ischemic hindlimb notably improved in the treatment groups (Fig. 2A) The laser Doppler perfusion index was significantly higher in the simvastatin group, the MSCs group and the combination group than in the control group on day 10 after treatment and showed further improvement afterwards on day 21 . The LDPI index was the highest in the combination group among the four 


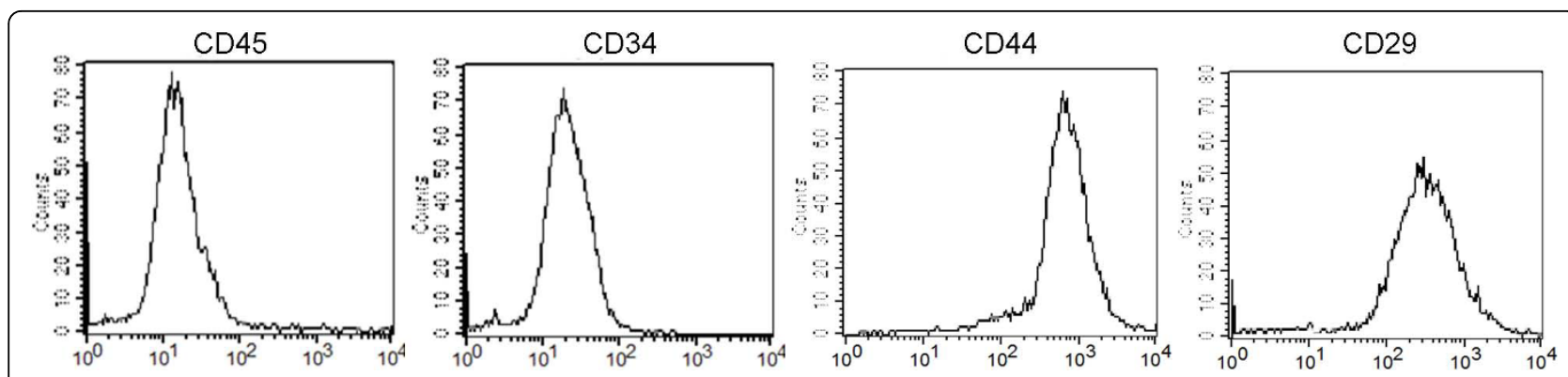

Figure 1 Characterization of bone marrow-derived MSCs. Flow cytometric analyses of bone marrow-derived MSCs. Cells were uniformly negative for CD34, CD45, and positive for CD44, and CD29.

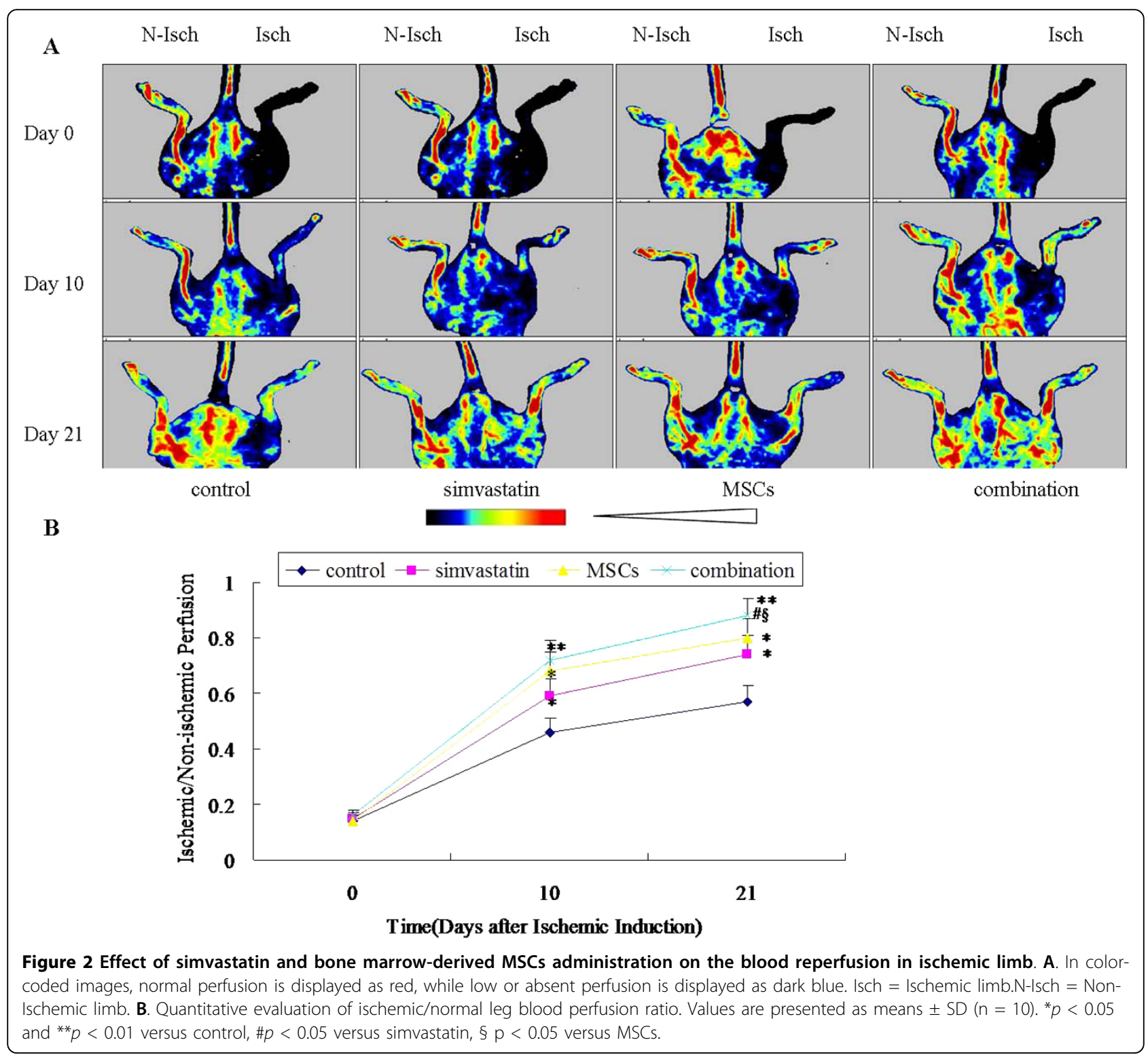


groups (Fig. 2B). The normal value of LDPI index was $1.00 \pm 0.03$ in this study.

\section{Combination therapy increases capillary density in the ischemic tissues}

To determine whether improved limb reperfusion by the simvastatin treatment or MSCs transplantation was linked with increased angiogenesis in vivo, the capillary/ muscle fiber ratio was assessed in the ischemic muscle at 3 weeks after the surgery by histochemical staining for alkaline phosphatase and image analysis (Fig. 3).The number of capillaries in each muscle fiber increased in the mice treated with either MSCs or simvastatin alone in comparison with the control group $(p<0.05)$. The combined administration of simvastatin and MSCs resulted in the highest capillary density ( $p<0.05$ vs. all other groups).

\section{Combination therapy enhances the differention of MSCs into endothelial cells in ischemic muscles}

To determine whether improved limb reperfusion by simvastatin and MSCs co-therapy was associated with differentiation into endothelial cells, the number of incorporated DiI-labeled MSCs (red labeling) into the mouse microvascular was detected by fluorescent staining against vWF (green labeling) (Fig. 4). Histological and quantitative analyses showed that the number of incorporated MSCs was significantly greater in the combination group relative to MSCs alone $(p<0.05)$.

\section{Combination therapy decreases cell apoptosis in vivo}

To determine whether improved limb reperfusion by the simvastatin/MSCs treatment was associated with increased ischemic muscle cells survival in vivo, the cell apoptosis was assessed in the ischemic muscle at days 21 after the treatment by TUNEL assay. Apoptosis as measured by TUNEL positive nuclei (Fig. 5) was significantly decreased in ischemic muscle of simvastatin and MSCs treated mice versus vehicle-treated mice. The cotreatment of simvastatin and MSCs resulted in a further decrease of cell apoptosis.

\section{Combination therapy enhances the expression of VEGF protein in ischemic tissue}

To examine whether high-dose simvastatin and MSCs co-therapy improved postischemic neovascularization, the expression of VEGF protein was detected by western blot assay. As can be seen in figure 6, the expression of VEGF significantly increased in the simvastatin group than in the control group $(p<0.05)$. Moreover, the expression of VEGF was higher in MSCs group compared with that in the simvastatin group, but was lower than that in the combination group $(p<0.05)$.

\section{Effect of simvastatin on the cell viability of bone marrow -derived MSCs in vitro}

In vitro, serum starvation induced bone marrow-derived MSCs apoptosis, as indicated by flow cytometry and MTT assay. When incubated with $0.01 \mu \mathrm{mol} / \mathrm{L}$ of simvastatin, the percentage of apoptotic cells decreased and the viability was visibly upregulated. However, pretreatment with $50 \mathrm{n}$ M wortmannin, a PI3-K inhibitor, diminished the anti-apoptotic effect of simvastatin (Fig. 7). The cell viability detected by MTT assay was significantly higher in simvastatin treated group than that in the control group. Although the cell viabilities were higher in simvastatin +

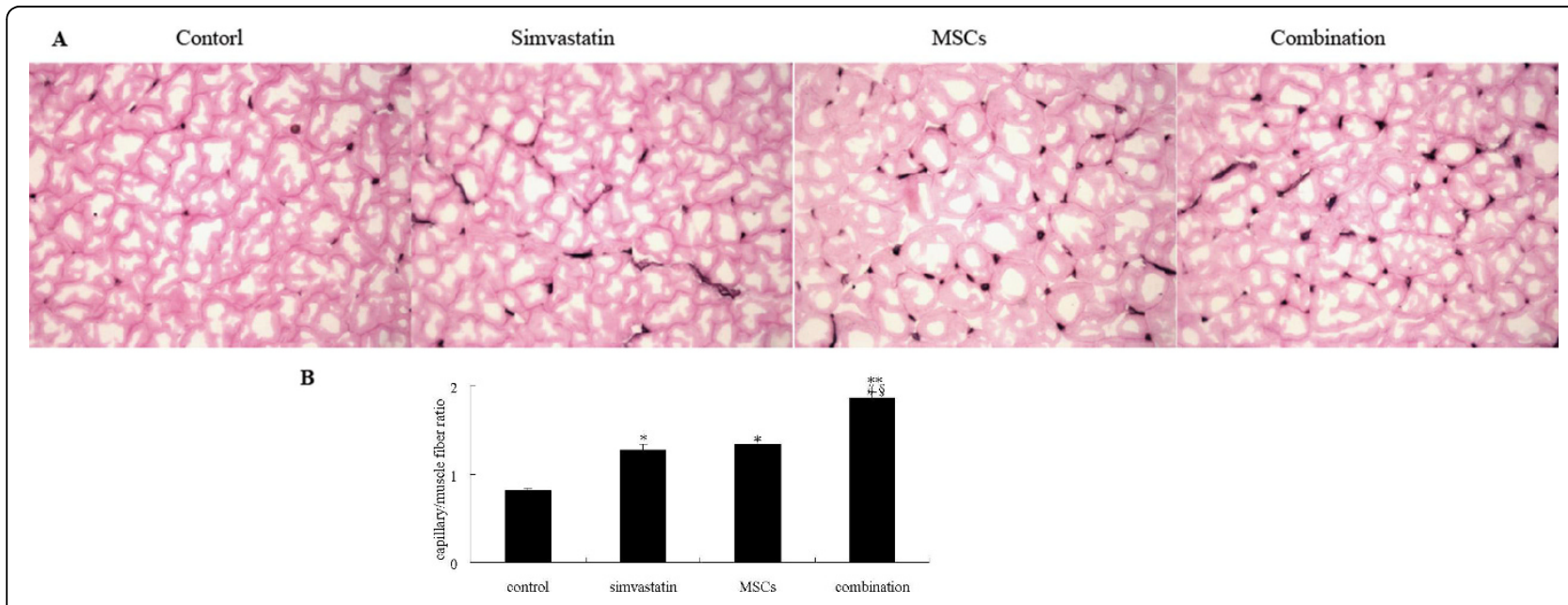

Figure 3 Effect of simvastatin and bone marrow-derived MSCs administration on angiogenesis in ischemic limb. A. Representative microphotographs of the section of ischemic hindlimb muscles stained histochemically for alkaline phosphatase, magnification $\times 400$. B. Quantitative analysis of capillary density in ischemic hindlimb muscles. Data are presented as mean $\pm \mathrm{SD}(\mathrm{n}=10) .{ }^{*} p<0.05$ and $\mathrm{d}^{* *} p<0.01$ versus control. \# $p<0.05$ versus simvastatin. $\S p<0.05$ versus MSCs. 


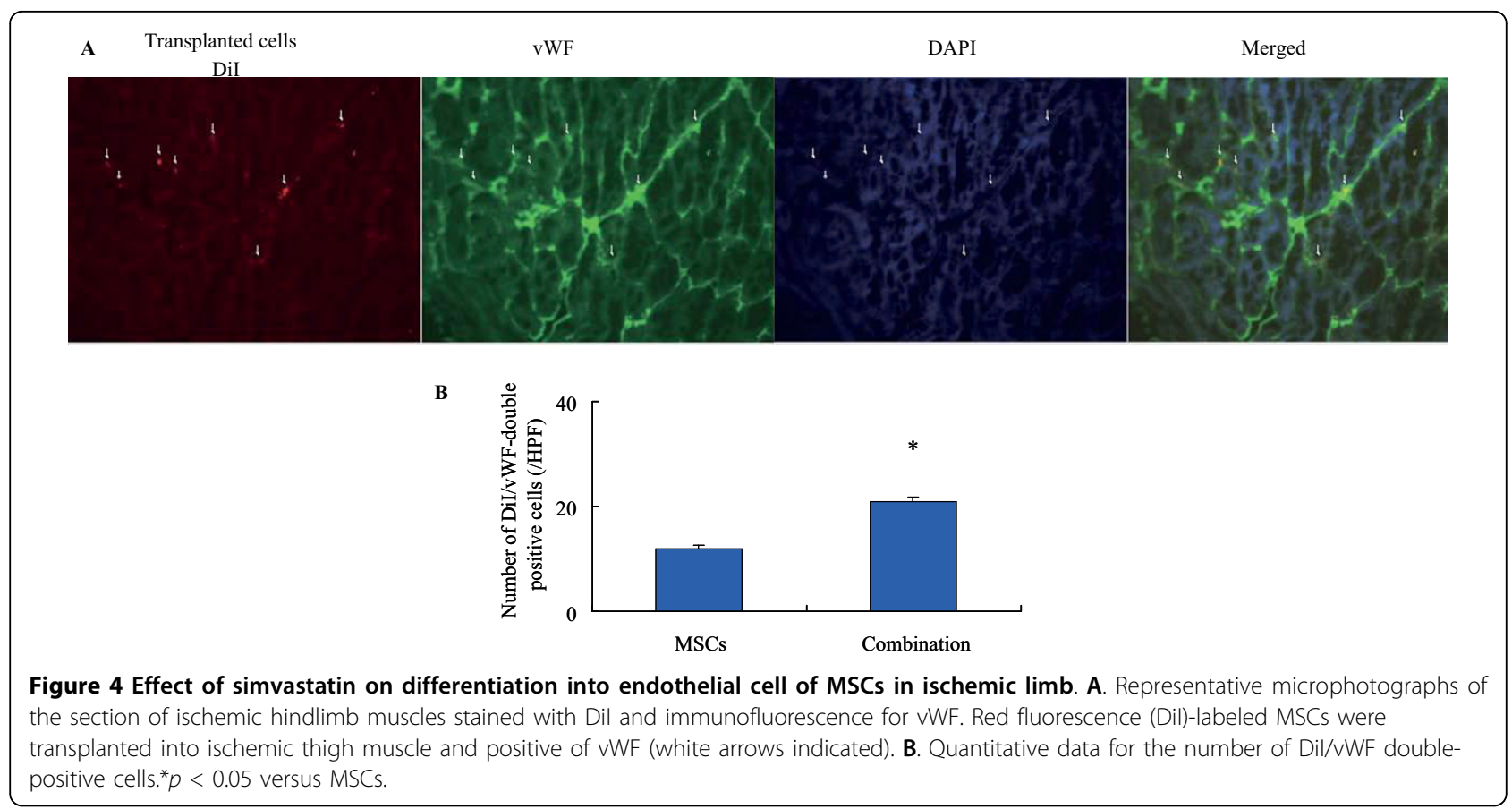

wortmannin group than those in the control group, there was no significant difference between the two groups. These results indicated that PI3-K pathway was of importance for the anti-apoptotic role of simvastatin.

\section{Effect of simvastatin on the VEGF releasing of bone marrow -derived MSCs in vitro}

To assess whether simvastatin affected the release of VEGF by MSCs, cells were cultured in the absence or presence of various concentration of simvastatin for $24 \mathrm{~h}$ and VEGF levels were measured in the conditioned medium using ELISA. Results found that VEGF levels were increased significantly in simvastatin-treated MSC cultures with a maximal effect at $0.01 \mu \mathrm{mol} / \mathrm{L}(78.1 \pm 5.4 \mathrm{pg} / \mathrm{ml})$ compared to control cultures $(38.6 \pm 2.2 \mathrm{pg} / \mathrm{ml}, p<0.05)$. The VEGF levels were reduced in 0.1 and $1.0 \mu \mathrm{mol} / \mathrm{L}$ simvastatin-treated MSCs cultures when compared with 0.01 $\mu \mathrm{mol} / \mathrm{L}$ simvastatin-treated cultures (Fig. 8).

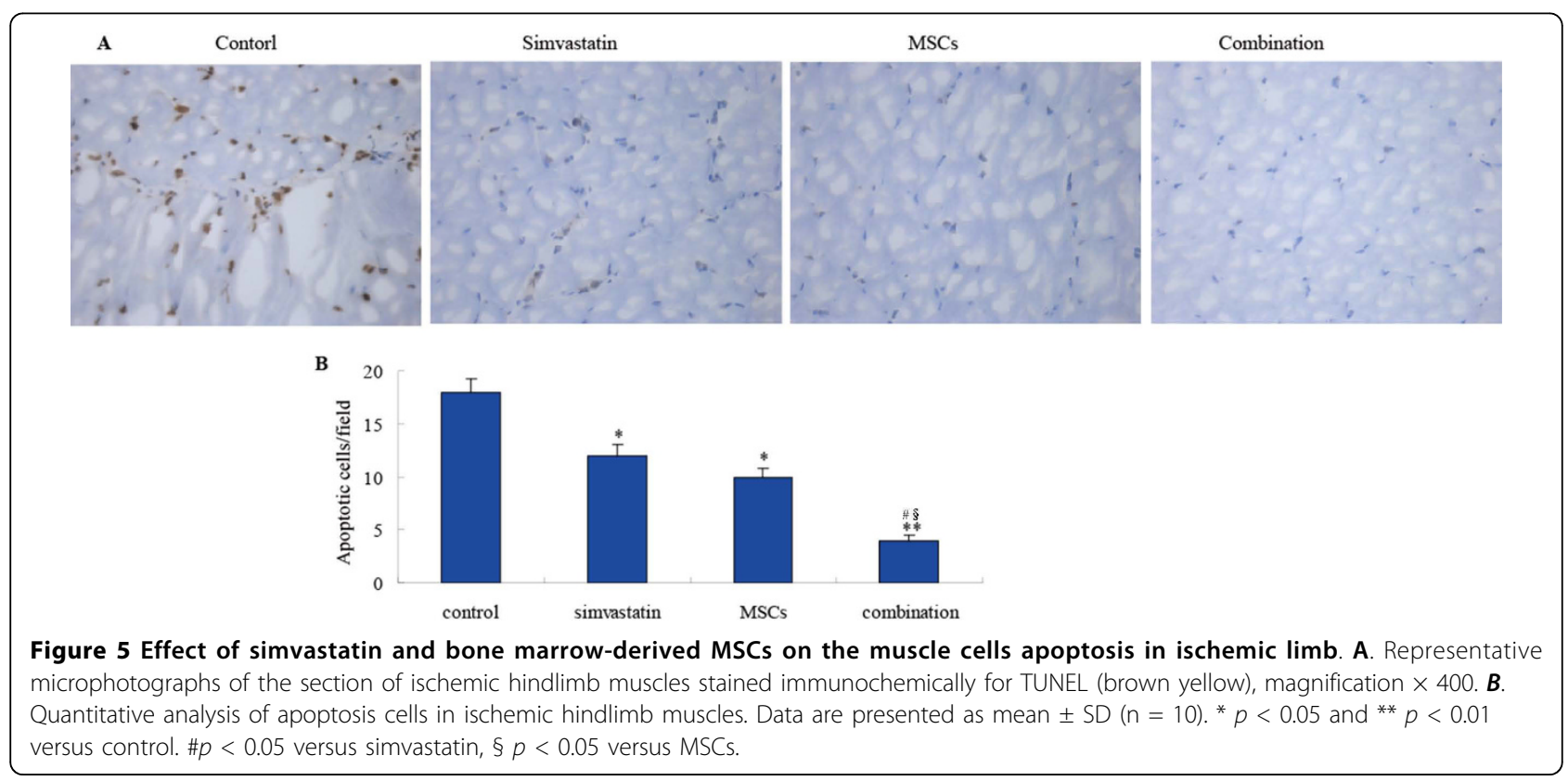




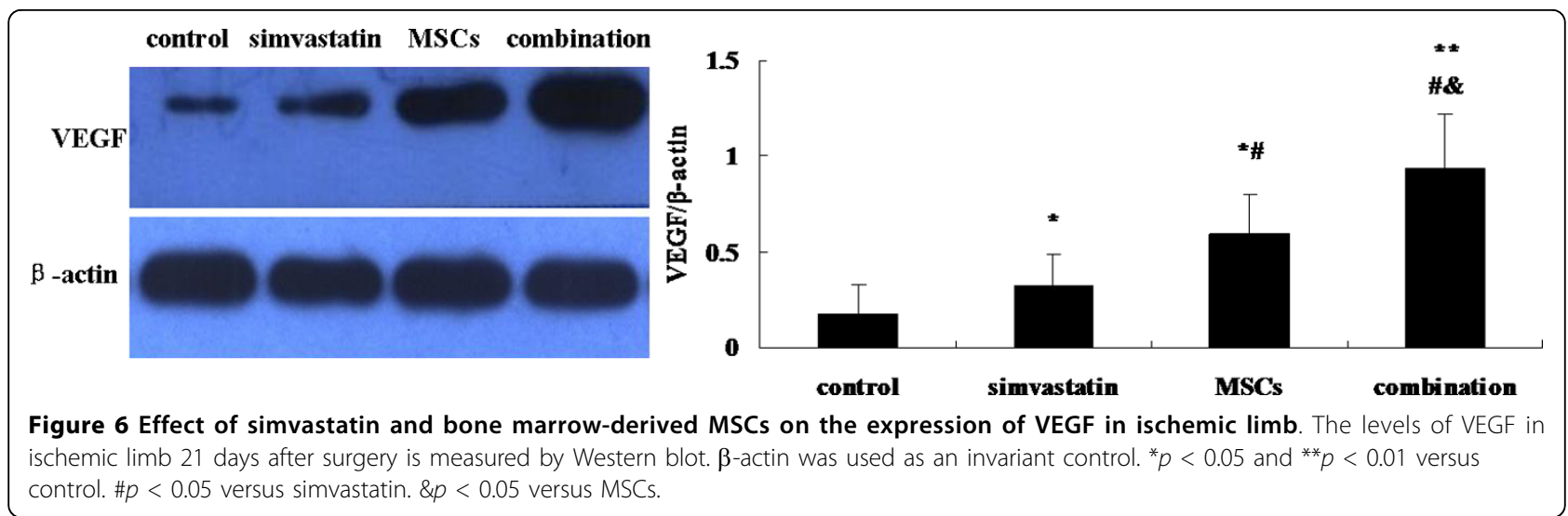

\section{Discussion}

The present study was designed to examine whether high-dose simvastatin could enhance the therapeutic effects of bone marrow-derived stem cells in the treatment of ischemic hindlimb. Overall, this study demonstrates more pronounced angiogenic response, decreased muscle cell apoptosis and improved blood reperfusion of ischemic muscle following combined therapy of highdose simvastatin and bone marrow-derived MSCs.
Bone marrow-derived MSCs have been identified as a potential new therapeutic option to induce therapeutic angiogenesis. The main advantage of using bone marrow-derived MSCs in treating ischemic disease is that they can be isolated from bone marrow by aspiration and expanded ex vivo before implantation. Under specialized culture conditions, bone marrow-derived MSCs have the capacity to differentiate into cells such as bone, cartilage, adipocytes and endothelial cells $[5,20,21]$.

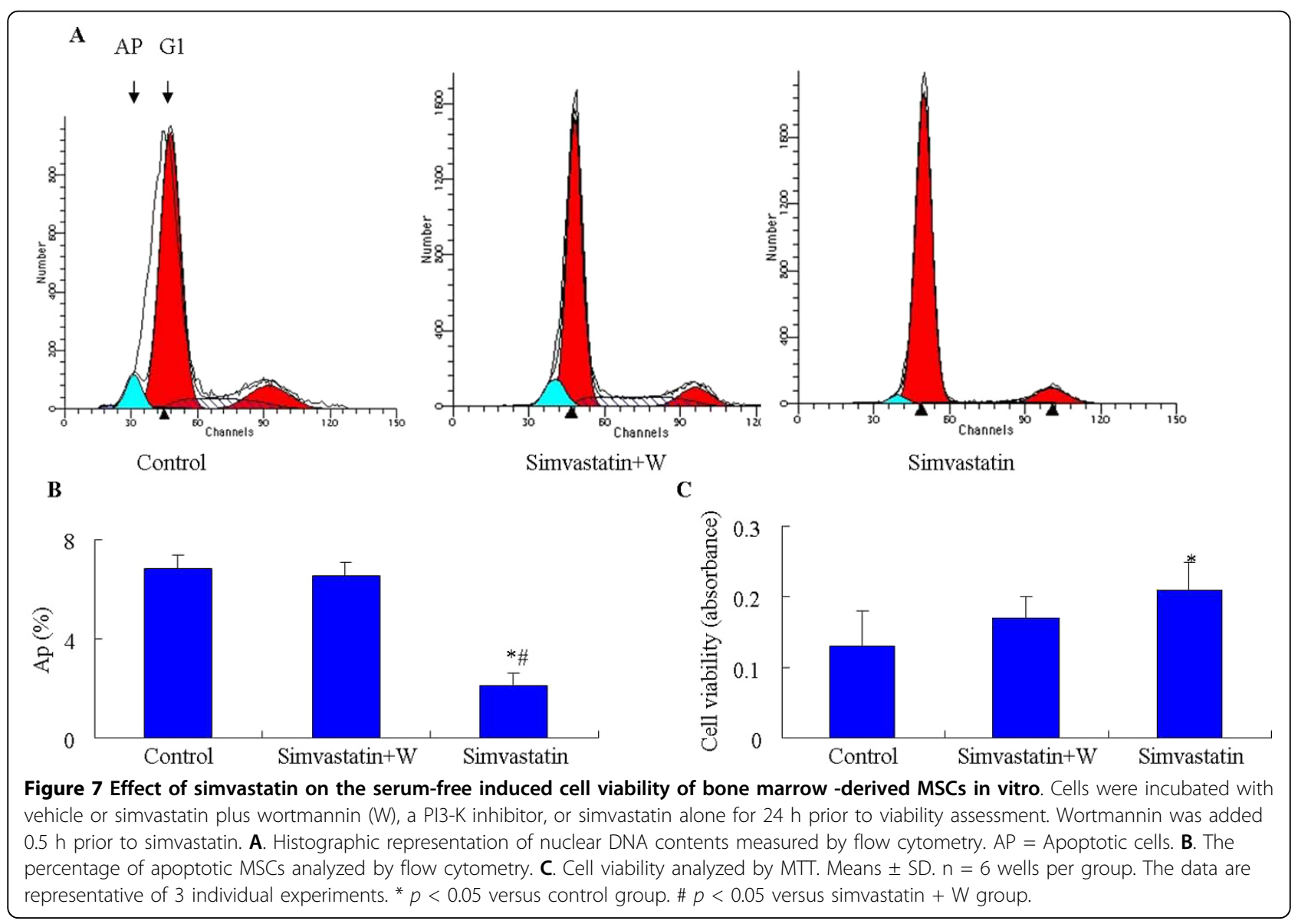




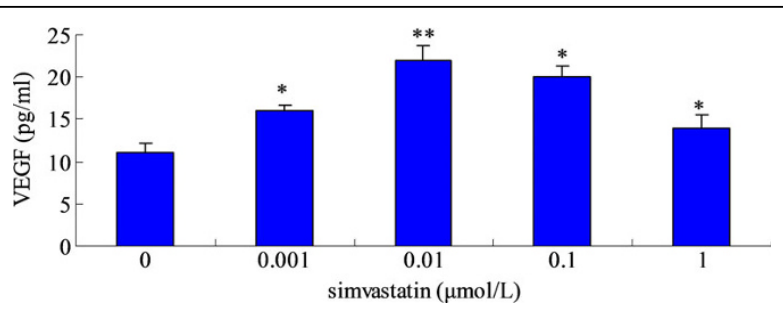

Figure 8 Effect of simvastatin on the release of VEGF by bone marrow-derived MSCs in vitro. MSCs were exposed to increasing doses of simvastatin for $24 \mathrm{~h}$. Then, $24 \mathrm{~h}$ after replacement of the culture medium, VEGF concentration was measured by ELISA. Means \pm SD of measurements from one experiment $(n=4) .{ }^{*} p<0.05$ versus untreated controls.

These results suggest that bone marrow-derived MSCs may be good candidates for cell transplantation. However, some patients are refractory to this cell therapy. Patients with PAD often accompany with several cardiovascular risk factors, such as aging, smoking, diabetes mellitus, et al, which impair the stem cell functions to varying degrees, likely limiting the efficiency of stem cell therapy. Therefore an approach to augment the angiogenic potency of bone marrow-derived MSCs transplantation is of great importance.

Statins, also known as the 3-hydroxy-3-methylglutaryl coenzyme A reductase inhibitors, are the first-line agents used in hypercholesterolemia[19]. They are also characterized by having other benefits apart from their lipid-lowering effects[22]. Among these pleiotropic effects are the anti-apoptotic and pro-angiogenic properties of statins. It has been demonstrated that statins could protect against ischemic injury of the heart and stimulate angiogenesis in ischemic limbs of normocholesterolemic animals. In the present study, we demonstrated that combination of MSCs transplantation and high-dose simvastatin treatment provided advanced benefits on treatment for hindlimb ischemic, compared with either treatment alone.

Combination treatment significantly enhanced capillary density in ischemic limbs than cell therapy alone. This may be partially due to the enhanced stem cells survival and greater differentiation rate of MSCs into vascular cells when administrated with simvastatin simultaneously. In vitro, a higher cell proliferation and decreased apoptosis under serum-free culture was demonstrated after bone marrow-derived MSCs incubated with simvastatin by MTT assay and flow cytometry measurement, respectively. An earlier study has demonstrated that ischemia and mechanical stress induce apoptosis of transplanted bone marrow cells [23]. In this in vitro study, we revealed that simvastatin inhibited serum starvation-induced MSC apoptosis, which may partly be blocked by wortmannin, a PI3-K inhibitor, indicating that the PI-3K/Akt pathway may be an important way in the regulation of MSCs apoptosis.

Enhanced expression of angiogenic growth factors in the ischemic tissue is another contributor to augment angiogenesis resulting from combinatorial treatment. It is well known [24-26] that bone marrow-derived MSCs could paracrine several angiogenic growth factors such as VEGF, etc. On the other hand, recent studies have demonstrated that statins strongly induced angiogenesis with increases in angiogenic cytokines [27,23]. In vitro, a higher expression of VEGF was detected in bone marrow-derived MSCs culture medium compared with blank control, indicating that MSCs could release a mount of angiogenic growth factors in hypoxic environment. Simultaneously, a highest expression of VEGF protein was detected in combination group in vivo. However, the release of VEGF by MSCs was reduced when the concentration of simvastatin increased in vitro. This indicated that the simvastatin has a biphasic dose-dependent effect on angiogenesis in vitro. Weis et al previously demonstrated that statins have proangiogenic effects at low therapeutic concentrations $(0.5 \mathrm{mg} /$ $\mathrm{kg} / \mathrm{d}$ of cerivastatin) but angiostatic effects at high concentrations $(2.5 \mathrm{mg} / \mathrm{kg} / \mathrm{d})$ in apolipoprotein E-deficient hypercholesterolemic C57BL/6J mice. In the present study, simvastatin augmented angiogenesis in response to acute ischemia at even a higher dose $(20 \mathrm{mg} / \mathrm{kg} / \mathrm{d})$. Masataka Sata has previously demonstrated [13] that high-dose statins $(5 \mathrm{mg} / \mathrm{kg} / \mathrm{d}$ cerivastatin) promoted blood flow recovery in the ischemic hind limb as determined by LDPI. In a stroke model in mice, atorvastatin (10 mg/kg/d) administered subcutaneously after stroke for 14 days brought about an improvement in neurologic recovery, which was related with an increase in VEGF, VEGF receptor 2, brain-derived neurotrophic factor, and endothelial cell proliferation in the ischemic territory [28]. A recent study revealed [29] that the same dose of simvastatin promoted angiogenesis in response to hypoxic conditions, but decreased angiogenesis mediated by inflammation. Therefore, it might be plausible that proangiogenic or antiangiogenic effects of statins might depend on distinct mechanisms of angiogenesis associated with inflammation, hypoxia, tissue ischemia, or cancer.

Promotion of limb muscle cells survival under hypoxic circumstance might be another contributor to improved blood reperfusion of ischemic muscle following combined therapy of simvastatin and bone marrow-derived MSCs. Apoptosis is defined as a programmed cell death or cell suicide, which determines the lifespan and coordinates the removal of cells. A line of evidence has been demonstrated $[30,31]$ that simvastatin and bone marrowderived MSCs both have the anti-apoptotic effects. Franke $\mathrm{C}$ has demonstrated [30] that simvastatin could 
upregulate the bcl-2 expression and enchance cells survival. Kortesidis and colleagues also demonstrated[31] that bone marrow derived-MSCs express factors that support cell survival and avoid apoptosis thereby preserving cells which would otherwise be destroyed. As indicated by TUNEL assay (Fig. 5), hindlimb muscle cells underwent severe ischemic apoptosis after artery occlusion. However, the apoptosis cells in ischemic muscle regions were significantly reduced after simvastatin and bone marrow-derived MSCs combined treatment.

Therefore, our study clearly demonstrated that bone marrow-derived MSCs in combination with high-dose simvastatin may be more effective or beneficial during the ischemic scenario than bone marrow-derived MSCs alone.

\section{Acknowledgements}

The Project was supported by grants from the China Postdoctoral Science Foundation funded project (No 20100471352 for DZ) and the Social Development Project of Wujin Bureau of Technology(No WS2009009 for YL)

\section{Author details}

'Department of Cardiology, the First Affiliated Hospital of Nanjing Medical University, 210029, R.R. China. ${ }^{2}$ Department of Cardiology, the Affiliated Wujin Hospital of Jiangsu University, 213002, P.R. China. ${ }^{3}$ The Research Center for Bone And Stem Cells, Nanjing Medical University, 210029, P.R. China. ${ }^{4}$ Department of Cardiology, the Affiliated Jiangning Hospital of Nanjing Medical University, 211100, P.R. China.

\section{Authors' contributions}

$Y L, D Z$ and $Y Z$ carried out the main experiment and drafted the manuscript. FZ and DZ conceived of the study and designed the experiment. GH helped to finish animal model and finished statistical analysis. All authors read and approved the final manuscript.

\section{Competing interests}

The authors declare that they have no competing interests.

Received: 11 July 2010 Accepted: 17 September 2010 Published: 17 September 2010

\section{References}

1. Diehm C, Allenberg JR, Pittrow D, Mahn M, Tepohl G, Haberl RL, Darius H, Burghaus I, Trampisch HJ: Mortality and vascular morbidity in older adults with asymptomatic versus symptomatic peripheral artery disease. Circulation 2009, 120:2053-2061.

2. Monreal M, Alvarez L, Vilaseca B, Coll R, Suarez C, Toril J, Sanclemente C: Clinical outcome in patients with peripheral artery disease. Results from a prospective registry (FRENA). Eur J Intern Med 2008, 19:192-197.

3. Pittenger MF, Mackay AM, Beck SC, Jaiswal RK, Douglas R, Mosca JD, Moorman MA, Simonetti DW, Craig S, Marshak DR: Multilineage potential of adult human mesenchymal stem cells. Science 1999, 284:143-147.

4. Dimmeler S, Leri A: Aging and disease as modifiers of efficacy of cell therapy. Circ Res 2008, 102:1319-1330.

5. Mackenzie TC, Flake AW: Human mesenchymal stem cells: insights from a surrogate in vivo assay system. Cells Tissues Organs 2002, 171:90-95.

6. Urbich $C$, Dimmeler $S$ : Risk factors for coronary artery disease, circulating endothelial progenitor cells, and the role of HMG-CoA reductase inhibitors. Kidney Int 2005, 67:1672-1676.

7. Kalinowski L, Dobrucki LW, Brovkovych V, Malinski T: Increased nitric oxide bioavailability in endothelial cells contributes to the pleiotropic effect of cerivastatin. Circulation 2002, 105:933-938.

8. Haendeler J, Hoffmann J, Zeiher AM, Dimmeler S: Antioxidant effects of statins via S-nitrosylation and activation of thioredoxin in endothelial cells: a novel vasculoprotective function of statins. Circulation 2004, 110:856-861.

9. Satoh K, Takaguri A, Itagaki M, Kano S, Ichihara K: Effects of rosuvastatin and pitavastatin on ischemia-induced myocardial stunning in dogs. J Pharmacol Sci 2008, 106:593-599.

10. Matsumura M, Fukuda N, Kobayashi N, Umezawa H, Takasaka A, Matsumoto T, Yao EH, Ueno T, Negishi N: Effects of atorvastatin on angiogenesis in hindlimb ischemia and endothelial progenitor cell formation in rats. J Atheroscler Thromb 2009, 16:319-326.

11. Weis M, Heeschen C, Glassford AJ, Cooke JP: Statins have biphasic effects on angiogenesis. Circulation 2002, 105:739-745.

12. Yang YJ, Qian HY, Huang J, Li JJ, Gao RL, Dou KF, Yang GS, Willerson JT, Geng YJ: Combined therapy with simvastatin and bone marrow-derived mesenchymal stem cells increases benefits in infarcted swine hearts. Arterioscler Thromb Vasc Biol 2009, 29:2076-2082.

13. Sata M, Nishimatsu H, Osuga J, Tanaka K, Ishizaka N, Ishibashi S, Hirata Y, Nagai R: Statins augment collateral growth in response to ischemia but they do not promote cancer and atherosclerosis. Hypertension 2004 43:1214-1220.

14. Jiang $Y$, Jahagirdar BN, Reinhardt RL, Schwartz RE, Keene CD, OrtizGonzalez XR, Reyes M, Lenvik T, Lund T, Blackstad M, Du J, Aldrich S, Lisberg A, Low WC, Largaespada DA, Verfaillie CM: Pluripotency of mesenchymal stem cells derived from adult marrow. Nature 2002, 418:41-49.

15. Hu Z, Zhang F, Yang Z, Yang N, Zhang D, Zhang J, Cao K: Combination of simvastatin administration and EPC transplantation enhances angiogenesis and protects against apoptosis for hindlimb ischemia. J Biomed Sci 2008, 15:509-517.

16. Couffinhal $T$, Silver $M$, Zheng $L P$, Kearney $M$, Witzenbichler $B$, Isner JM Mouse model of angiogenesis. Am J Pathol 1998, 152:1667-1679.

17. Yao Y, Zhang F, Wang L, Zhang G, Wang Z, Chen J, Gao X: Lipopolysaccharide preconditioning enhances the efficacy of mesenchymal stem cells transplantation in a rat model of acute myocardial infarction. J Biomed Sci 2009, 16:74.

18. Tan Y, Shao H, Eton D, Yang Z, Alonso-Diaz L, Zhang H, Schulick A, Livingstone AS, Yu H: Stromal cell-derived factor-1 enhances proangiogenic effect of granulocyte-colony stimulating factor. Cardiovasc Res 2007, 73:823-832.

19. Sadowitz B, Maier KG, Gahtan V: Basic science review: Statin therapy-Part I: The pleiotropic effects of statins in cardiovascular disease. Vasc Endovascular Surg 2010, 44:241-251.

20. Tang J, Xie Q, Pan G, Wang J, Wang M: Mesenchymal stem cells participate in angiogenesis and improve heart function in rat model of myocardial ischemia with reperfusion. Eur I Cardiothorac Surg 2006, 30:353-61

21. Zimmet $J M$, Hare $J M$ : Emerging role for bone marrow derived mesenchymal stem cells in myocardial regenerative therapy. Basic Res Cardiol 2005, 100:471-481.

22. Futterman $L G$, Lemberg $L:$ Statin pleiotropy: fact or fiction? Am $J$ Crit Care 2004, 13:244-249.

23. Bitto A, Minutoli L, Altavilla D, Polito F, Fiumara T, Marini H, Galeano M, Calo M, Lo Cascio P, Bonaiuto M, Migliorato A, Caputi AP, Squadrito F: Simvastatin enhances VEGF production and ameliorates impaired wound healing in experimental diabetes. Pharmacol Res 2008, 57:159-169.

24. Cheng AS, Yau TM: Paracrine effects of cell transplantation: strategies to augment the efficacy of cell therapies. Semin Thorac Cardiovasc Surg 2008, 20:94-101

25. Chen L, Tredget EE, Wu PY, Wu Y: Paracrine factors of mesenchymal stem cells recruit macrophages and endothelial lineage cells and enhance wound healing. PLOS One 2008, 3:e1886.

26. Gnecchi M, He H, Noiseux N, Liang OD, Zhang L, Morello F, Mu H, Melo LG, Pratt RE, Ingwall JS, Dzau VJ: Evidence supporting paracrine hypothesis for Akt-modified mesenchymal stem cell-mediated cardiac protection and functional improvement. FASEB J 2006, 20:661-669.

27. Moreno PR, Sanz J, Fuster V: Promoting mechanisms of vascular health: circulating progenitor cells, angiogenesis, and reverse cholesterol transport. J Am Coll Cardiol 2009, 53:2315-2323.

28. Chen J, Zhang C, Jiang H, Li Y, Zhang L, Robin A, Katakowski M, Lu M, Chopp M: Atorvastatin induction of VEGF and BDNF promotes brain plasticity after stroke in mice. J Cereb Blood Flow Metab 2005, 25:281-290. 
29. Zhu XY, Daghini E, Chade AR, Lavi R, Napoli C, Lerman A, Lerman LO: Disparate effects of simvastatin on angiogenesis during hypoxia and inflammation. Life Sci 2008, 83:801-809.

30. Franke C, Noldner M, Abdel-Kader R, Johnson-Anuna LN, Gibson Wood W, Muller WE, Eckert GP: BCl-2 upregulation and neuroprotection in guinea pig brain following chronic simvastatin treatment. Neurobiol Dis 2007, 25:438-445.

31. Kortesidis A, Zannettino A, Isenmann S, Shi S, Lapidot T, Gronthos S: Stromal-derived factor-1 promotes the growth, survival, and development of human bone marrow stromal stem cells. Blood 2005, 105:3793-3801.

doi:10.1186/1423-0127-17-75

Cite this article as: Li et al:: Augmentation of neovascularization in

murine hindlimb ischemia by combined therapy with simvastatin and bone marrow-derived mesenchymal stem cells transplantation. Journal of Biomedical Science 2010 17:75.

\section{Submit your next manuscript to BioMed Central} and take full advantage of:

- Convenient online submission

- Thorough peer review

- No space constraints or color figure charges

- Immediate publication on acceptance

- Inclusion in PubMed, CAS, Scopus and Google Scholar

- Research which is freely available for redistribution

Submit your manuscript at www.biomedcentral.com/submit 